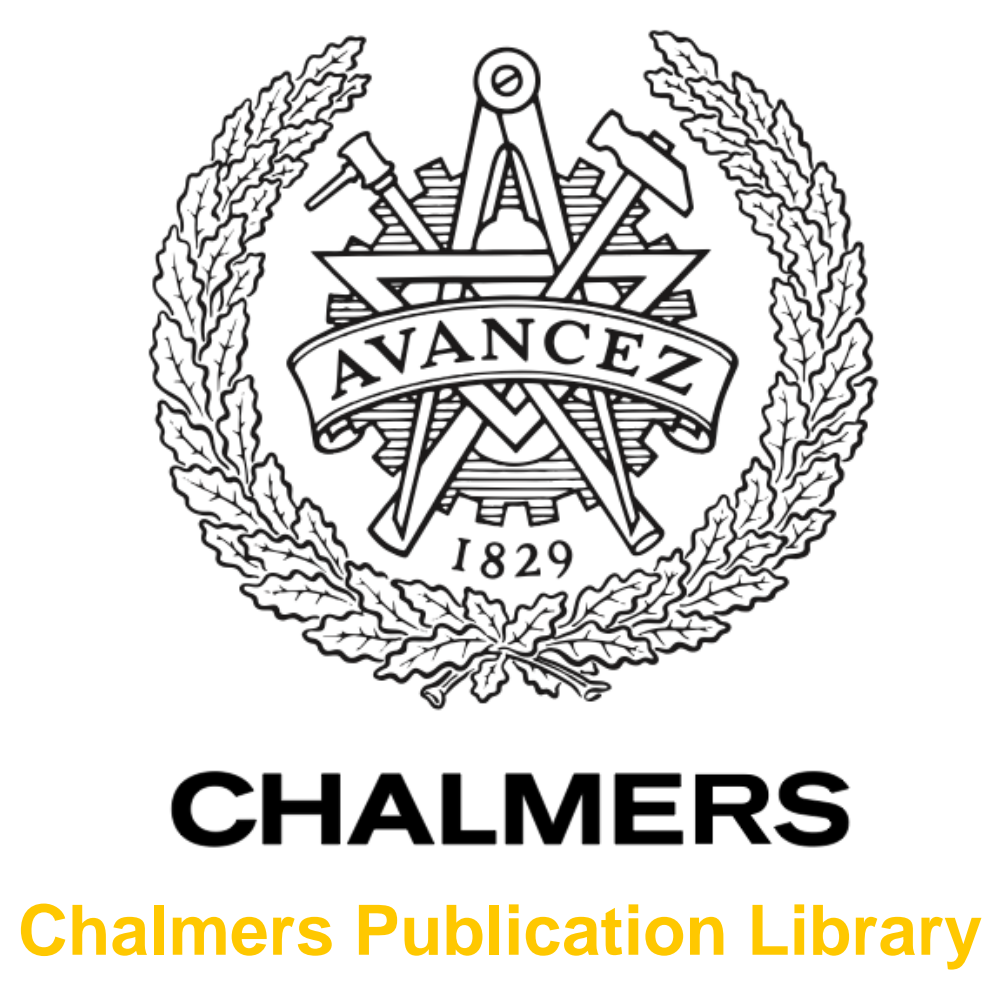

\title{
Storage Stability of Bio-oils Derived from the Catalytic Conversion of Softwood Kraft Lignin in Subcritical Water
}

This document has been downloaded from Chalmers Publication Library (CPL). It is the author's version of a work that was accepted for publication in:

Energy \& Fuels (ISSN: 0887-0624)

Citation for the published paper:

Lyckeskog, H. ; Mattsson, C. ; Åmand, L. et al. (2016) "Storage Stability of Bio-oils Derived from the Catalytic Conversion of Softwood Kraft Lignin in Subcritical Water". Energy \&

Fuels, vol. 30(4), pp. 3097-3106.

http://dx.doi.org/10.1021/acs.energyfuels.6b00087

Downloaded from: http://publications.lib.chalmers.se/publication/237305

Notice: Changes introduced as a result of publishing processes such as copy-editing and formatting may not be reflected in this document. For a definitive version of this work, please refer to the published source. Please note that access to the published version might require a subscription. 


\title{
Storage Stability of Bio-oils Derived from the Catalytic Conversion of Softwood Kraft Lignin in Subcritical Water
}

\author{
Huyen Nguyen Lyckeskog, ${ }^{\dagger}$ Cecilia Mattsson, ${ }^{\dagger}$ Lars-Erik Åmand, ${ }^{\ddagger}$ Lars Olausson, ${ }^{\S}$ \\ Sven-Ingvar Andersson, ${ }^{\dagger}$ Lennart Vamling, ${ }^{\ddagger}$ and Hans Theliander*, ${ }^{\dagger}$ \\ ${ }^{\dagger}$ Department of Chemistry and Chemical Engineering, Chalmers University of Technology, SE-412 96 Gothenburg, Sweden \\ ${ }^{\ddagger}$ Department of Energy and Environment, Chalmers University of Technology, SE-412 96 Gothenburg, Sweden \\ ${ }^{\S}$ Valmet Power AB, Box 8734, SE-402 75 Gothenburg, Sweden
}

\begin{abstract}
The stability of lignin-derived bio-oil obtained from a continuous process $\left[\right.$ base $\left(\mathrm{K}_{2} \mathrm{CO}_{3}\right)$-catalyzed, using phenol as a capping agent] under subcritical conditions of water $\left(25 \mathrm{MPa}, 290-370{ }^{\circ} \mathrm{C}\right)$ was investigated. The lignin-derived bio-oil obtained was stored at ambient temperature for 2 years. Our results show that the base concentration in the feed solution affects the stability of this lignin-derived bio-oil during its long-term storage. It was found that, at low base concentrations (i.e., $0.4 \%-$ $1.0 \%)$, the yields of all lignin-derived bio-oil fractions were relatively stable. At high base concentrations (i.e., 1.6\%-2.2\%), however, the yield of high-molecular-weight (high-Mw) structures increased and that of low-molecular-weight (low-Mw) structures decreased after storage. This indicated that the low-Mw materials had been polymerized to form high-Mw materials. In addition, it was found that the yield of gas chromatography-mass spectrometry (GC-MS)-identified compounds (excluding phenol) in this lignin-derived bio-oil decreased from $15 \%$ to $11 \%$. This is probably due to the presence of solids in these ligninderived bio-oils, which promotes the catalytic polymerization reactions, suggesting that it is beneficial to remove the solids from this lignin-derived bio-oil in order to enhance its stability. Compared to the results obtained from bio-oil derived from biomass pyrolysis, our results show that bio-oil derived from the conversion of lignin in subcritical water has better chemical stability during long-term storage.
\end{abstract}

\section{INTRODUCTION}

All products that are currently produced from oil can, in principle, be produced from biomass, which is a renewable and sustainable raw material. The most common sources of biomass are forestry and agricultural crops and their residues, animal and industrial residues, and sewage and municipal solid waste. ${ }^{1}$ Biomass consists of three main components: cellulose, hemicelluloses, and lignin. Cellulose is a linear homopolymer of glucose units with a very high degree of polymerization (from 10000 in native wood to 1000 in bleached Kraft pulps); hemicelluloses are heterogeneous polymers of sugar monomers with a low degree of polymerization (100-200); and lignin is an irregular, branched phenolic macromolecule. ${ }^{2,3}$ Several different conversion processes have been suggested, ${ }^{4}$ each of which is suitable for a specific application. One type that can be used to recover energy from biomass is thermochemical conversion, comprising combustion, gasification, and pyrolysis. ${ }^{4,5}$ Fast pyrolysis, which uses high heating rates $(\sim 1000 \mathrm{~K} /$ $\mathrm{s})$, moderate temperatures $\left(450-550{ }^{\circ} \mathrm{C}\right)$, and short residence times $(0.5-5 \mathrm{~s})$ in the absence of oxygen, is one of the methods studied most for producing pyrolysis bio-oil from biomass; it has been found to give products of higher quality than other thermochemical processes. ${ }^{6,7}$ The pyrolysis bio-oil obtained is a viscous liquid with a smoky odor that is comprised of a wide range of compounds from the depolymerization and degradation of cellulose, hemicelluloses, and lignin. ${ }^{8}$ Compared to conventional fossil fuels (see Table 1), bio-oils produced from the fast pyrolysis of biomass are composed of a large number of oxygenated hydrocarbons with a high oxygen content, considerable water concentration, and low calorific value
Table 1. Basic Properties of Lignin-Derived Bio-oil, Biomass-Pyrolysis Bio-Oil, and Fossil Fuel ${ }^{a}$

\begin{tabular}{|c|c|c|c|}
\hline fuel property & $\begin{array}{c}\text { lignin-derived } \\
\text { bio-oil }^{b}\end{array}$ & $\begin{array}{c}\text { biomass-pyrolysis } \\
\text { bio-oil }^{c}\end{array}$ & $\begin{array}{l}\text { fossil } \\
\text { fuel }\end{array}$ \\
\hline water content (\%) & $11-19$ & $20-30$ & 0.1 \\
\hline ash (\%) & $1.0-3.5$ & $0.1-0.5$ & $>0.3$ \\
\hline \multicolumn{4}{|l|}{ elemental composition } \\
\hline C (\%) & $70-76$ & $32-50$ & $85-86$ \\
\hline $\mathrm{H}(\%)$ & $6.1-6.9$ & $8-11$ & $\begin{array}{c}12.5- \\
14\end{array}$ \\
\hline $\mathrm{N}(\%)$ & $<0.1$ & $<0.4$ & 0.2 \\
\hline $\mathrm{O}(\%)$ & $15-21$ & $45-60$ & 1 \\
\hline S (\%) & 0.39 & $<0.3$ & $>1$ \\
\hline $\begin{array}{l}\text { high heating value, HHV } \\
(\mathrm{MJ} / \mathrm{kg})\end{array}$ & $31-33$ & $15-18$ & $39-41$ \\
\hline
\end{tabular}

(high heating value, HHV). However, the composition of this pyrolysis bio-oil means that it has poor chemical and thermal stability during storage, which creates difficulties in its utilization, compared to conventional fossil fuel. ${ }^{9,10}$

Lignin, which is one of the major components of lignocellulosic biomass, is underused today, although it has gained growing attention as a raw material in the production of transportation fuels, chemicals, and materials, because of its

Received: January 13, 2016

Revised: March 15, 2016

Published: March 21, 2016 


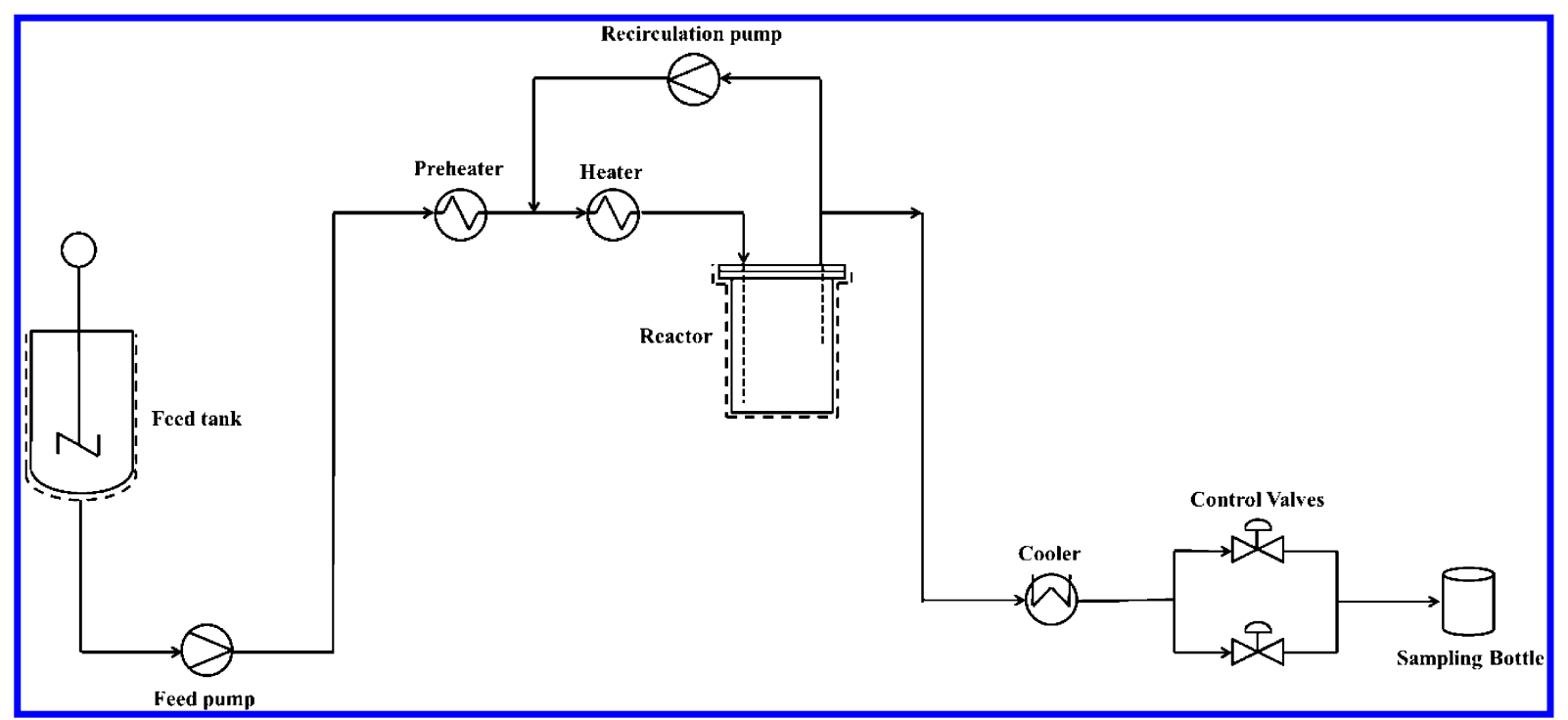

Figure 1. Schematic flow sheet of the conversion process in subcritical water.

aromatic nature and its abundant availability. ${ }^{11,12}$ Native lignin consists of aromatic units (such as p-coumaryl alcohol, coniferyl alcohol, and sinapyl alcohol) connected randomly with ether $(\mathrm{C}-\mathrm{O}-\mathrm{C})$ and carbon-carbon $(\mathrm{C}-\mathrm{C})$ bonds. In the Kraft pulping process, lignin is dissolved from wood and used as a low-grade boiler fuel to provide heat and power for the process itself. Native and Kraft lignin differ not only because most of the $\beta$-O- 4 structures $(>95 \%)$ are hydrolyzed in the process, but also in that new carbon-carbon bonds are formed (i.e., the lignin is partly condensed). ${ }^{2}$ Nowadays, a new process known as "LignoBoost", which is used to extract lignin from black liquor, has gained commercial status and, therefore, a vast amount of Kraft lignin is expected to be available for valorization in the future. Among the processes suitable for converting lignin into smaller aromatic units, hydrothermal conversion in subcritical water is very promising, because the relatively mild operating temperatures allow the aromatic structures to be retained. ${ }^{13}$ In order to limit the formation of solid residues and increase the yield of liquid products (ligninderived bio-oils), our earlier studies used phenol as the capping agent, alkali catalyst (e.g., $\mathrm{K}_{2} \mathrm{CO}_{3}$ ) as the homogeneous catalyst, and zirconia $\left(\mathrm{ZrO}_{2}\right)$ as the heterogeneous catalyst. These studies investigated the effects of $\mathrm{K}_{2} \mathrm{CO}_{3}$ concentration and operating temperature on the conversion of Kraft lignin in subcritical water. ${ }^{13,14}$ The yields of this bio-oil and char obtained from these lignin conversions were $\sim 69 \%-87 \%$ and $16 \%-22 \%$, respectively. Compared to biomass-pyrolysis bio-oil, lignin-derived bio-oil has the characteristics of lower oxygen and water contents and higher calorific value (see Table 1). Moreover, lignin-derived bio-oil has low contents of both nitrogen and sulfur, with values of $<0.1 \%$ and $\sim 0.4 \%$, respectively, which give lower emissions of $\mathrm{SO}_{2}$ and $\mathrm{NO}_{x}$ than conventional fossil fuel. These characteristics make lignin-derived bio-oil advantageous in the production of transportation fuel. However, the characteristics of high concentrations of active organic functional groups (i.e., aromatic rings, $(-\mathrm{OH})$ and $\left(-\mathrm{OCH}_{3}\right)$ groups and unsaturated bonds such as $\mathrm{C}=\mathrm{C}$ or $\mathrm{C}=\mathrm{O})$ and ash (1.0-3.5\%) remain. Their presence may cause changes in the physical and chemical properties of lignin-derived bio-oils that results in low storage stability. ${ }^{9,10}$
The storage stability of bio-oil is a factor that significantly affects bio-oil applications in industry. Here, the term "storage stability" refers to the ability of bio-oil to retain its original physical and chemical properties in a relatively high-temperature environment (thermal stability) or under atmospheric (or oxygen) oxidation (oxidative stability) conditions. It has been found that the biomass-pyrolysis bio-oil experiences an increase in its viscosity, water content, average molecular weight, loss of volatiles, and phase separation after storage., ${ }^{9,10}$ Yang et al. ${ }^{10}$ proposed that bio-oil derived from the fast pyrolysis of biomass is still highly active during storage, because a thermodynamic equilibrium is not reached and it retains a high level of acidity. Therefore, this type of pyrolysis bio-oil has a tendency to undergo internal reactions such as polymerization, condensation, esterification, and oxidation at ambient temperature after it has been collected. Heating this pyrolysis bio-oil will accelerate the aging effect, because the chemical reactions continue at a faster rate: these aging reactions contribute to the instability of such pyrolysis bio-oil., ${ }^{9,15,16}$ Their stability could be improved during storage by using not only physical methods (such as drying the biomass, removing ash and char, adding solvent, adding antioxidant and emulsification) but also chemical methods (such as catalytic cracking, catalytic hydrodeoxygenation, and catalytic esterification)., 10 Chaala et al., ${ }^{17}$ who investigated the storage stability of pyrolysis bio-oils obtained by vacuum pyrolysis of softwood bark, reported that after 6 months of storage at room temperature, its solids content had increased from $0.55 \%$ to $0.84 \%$; the same tendency was found for viscosity, while the water content did not show any clear changes. In terms of molecular weight, it was shown that the amount of compounds with a molecular weight $(\mathrm{Mw})$ of $<400$ decreased by $8 \%$, while those with $\mathrm{Mw}>500$ increased by $8 \%$. In another study on the stability of pyrolysis bio-oils from pine, spruce, and forestry residue stored for 6 months at room temperature, Oasmaa et al. ${ }^{18}$ showed that the water content increased from $27 \%$ to $30 \%$ while the solids content remained constant. Increases in viscosity and the average molecular weight were also observed in this pyrolysis bio-oil. Czernik et al. ${ }^{19}$ concluded that the water content, viscosity, and molecular weight of bio-oil from the fast pyrolysis of wood increased with storage time and temperature; they also found that its $\mathrm{pH}$ was not affected by 
Table 2. Operating and Feed Conditions Varied in the Subcritical Water of the LignoBoost Kraft Lignin

\begin{tabular}{|c|c|c|c|c|c|c|c|c|c|}
\hline & \multicolumn{4}{|c|}{$\mathrm{K}_{2} \mathrm{CO}_{3}$ Concentration Series } & \multicolumn{5}{|c|}{ Reaction Temperature Series } \\
\hline & A & B & $\mathrm{C}$ & $\mathrm{D}$ & $\mathrm{F}$ & G & $\mathrm{H}$ & $\mathrm{C}$ & I \\
\hline temperature, $T\left({ }^{\circ} \mathrm{C}\right)$ & 350 & 350 & 350 & 350 & 290 & 310 & 330 & 350 & 370 \\
\hline $\mathrm{K}_{2} \mathrm{CO}_{3}$ content $(\%)$ & 0.4 & 1.0 & 1.6 & 2.2 & 1.6 & 1.6 & 1.6 & 1.6 & 1.6 \\
\hline
\end{tabular}

storage. Bridgwater ${ }^{15}$ and Zhang et al. ${ }^{16}$ reported that solid or char residues in the pyrolysis bio-oil contain ash (comprised mainly of alkali metals, notably potassium and sodium), which is catalytically active and thus enhances secondary reactions that affect its aging. These authors also stated that other elements in ash, such as chlorine, nitrogen, and sulfur, gives the same catalytic effect on the aging of pyrolysis bio-oil. Furthermore, Czernik and Bridgwater ${ }^{20}$ noted that the pyrolysis bio-oil is highly sensitive to heat and oxygen, because it contains compounds that are more reactive at elevated temperature and in the presence of oxygen. These previous papers contributed to the understanding of the storage stability of pyrolysis bio-oil in general and biomass-pyrolysis bio-oil in particular. However, to the author's knowledge, there is no literature so far that has focused on the storage stability of lignin-derived bio-oil.

The present study aims at investigating the stability of the bio-oil obtained from the conversion of softwood Kraft lignin under subcritical water conditions. The lignin-derived bio-oil was stored at an ambient temperature in long-term storage for a period of 1 or 2 years. The changes in water concentration and chemical composition, together with the molecular weight of these bio-oils, are evaluated before and after the 1-2 years of storage.

\section{MATERIALS AND METHOD}

2.1. Materials. The bio-oil samples used in this work came from the continuous conversion of LignoBoost Kraft lignin in subcritical water. This Kraft lignin (from the demonstration plant in Bäckhamar, Sweden) had a moisture content of $32.6 \%$ and carbon, hydrogen, sulfur, potassium, and ash contents of $65.6 \%, 5.7 \%, 1.85 \%, 0.07 \%$ and $0.8 \%$, respectively. The oxygen content of this lignin was $\sim 26 \%$ (calculated value), the $\mathrm{HHV}$ was $27.7 \mathrm{MJ} / \mathrm{kg}$, and the mass-average molar mass $(\mathrm{Mw})$ was $3900 \mathrm{~g} / \mathrm{mol}$, with a molar-mass dispersity of 5.6. The conversion process where the lignin-derived bio-oils were produced is shown in Figure 1. During the experimental runs, the feed slurry was pumped continuously at a flow rate of $1 \mathrm{~kg} / \mathrm{h}$ from a $10 \mathrm{~L}$ stirred tank, which was kept at $40{ }^{\circ} \mathrm{C}$. Prior to entering the reactor, the feed was preheated to $80^{\circ} \mathrm{C}$ and then mixed with the recirculation stream of reaction products. The recycle-to-feed ratio was set at $\sim 10$, with the exception of Run I $\left(370{ }^{\circ} \mathrm{C}\right)$, where this value was set at 2 , because of the operational problems. The mixture then passed through another heater that adjusted its temperature to the reaction temperature. The reaction pressure was fixed at $25 \mathrm{MPa}$. The reaction mixture was in contact with the solid catalyst $\left(\mathrm{ZrO}_{2}\right.$ pellets $)$ while flowing upward in the $500 \mathrm{~cm}^{3}$ fixed-bed reactor that was equipped with an electrically heated jacket. The free volume of the reactor charged with catalysts was $294 \mathrm{~cm}^{3}$, which gave a reaction residence time $(\tau)$ in the range of $10-13 \mathrm{~min}$, depending on the temperature of the reactor. The reaction products were cooled and depressurized to ambient conditions through two pressure control valves installed in parallel. The steady-state samples collected after $\sim 2 \mathrm{~h}$ from the start of operation consisted of two distinct liquid phases: an aqueous phase and an oil phase. They were separated by using a centrifugation operating at $492 \mathrm{rad} / \mathrm{s}$ for $3 \mathrm{~h}$ and at $25^{\circ} \mathrm{C}$. All of the aqueous samples were mixed into one single aqueous sample, and the same was done with the oil samples. These samples thus represent the average values during the steady-state period. In all of the experiments, the dry lignin content was $\sim 5.6 \%$ and the ratio of phenol to dry lignin was in the range of $0.73-0.75$. A total of nine runs were carried out: in four runs (A-D), the concentration (or mass fraction) of $\mathrm{K}_{2} \mathrm{CO}_{3}$ in the feed was varied from $0.4 \%$ to $2.2 \%$ and in the remaining five runs $(\mathrm{F}-\mathrm{I})$, the operating temperature was varied from $290{ }^{\circ} \mathrm{C}$ to $370{ }^{\circ} \mathrm{C}$. Further details of the apparatus and procedure related to the production of lignin-derived bio-oil are reported in previous work by Nguyen et al. ${ }^{13,14}$ The operating and feed conditions that were varied are reported in Table 2.

2.2. Bio-oil Storage. The stability of bio-oil can be investigated through storage time and/or storage temperature: ${ }^{5}$ the current study investigates the former (i.e., long-term storage of bio-oils). The ligninderived bio-oils samples were stored in a dark locker at ambient temperature for a period of $\sim 1-2$ years to evaluate the effect of natural aging. Their physical and chemical properties were measured first at a fresh state and then after long-term storage.

2.3. Bio-oil Characterization. 2.3.1. Water Content. The ligninderived bio-oil samples were first dissolved in tetrahydrofuran (THF) with a solvent-to-feed ratio $(\mathrm{S} / \mathrm{F})$ of $\sim 20 / 1$. Their water content was then measured by Karl Fischer volumetric titration, using HydranalComposite 5 and methanol; the titrant concentration was determined using Hydranal Water Standard 10.0. Additional details about this method can be found in the work of Nguyen et al. ${ }^{13,14}$

2.3.2. Elemental Analysis and Heating Value. The elemental composition, ash content, and HHV of the fresh lignin-derived bio-oils were analyzed at SP (The Swedish Technical Research Institute) in Boras, Sweden. The elemental composition of the stored ligninderived bio-oils was determined at Mikroanalytisches' Laboratorium Kolbe (Germany), which uses a CHNOS analyzer (from Elementar) to measure the carbon and hydrogen contents, an ion chromatography (IC) system (from Metrohm) was used to measure the sulfur content, and an atomic absorption spectroscopy (AAS) system was used to measure the potassium content. The ash content of the stored ligninderived bio-oils was measured twice, in accordance with the SCAN-C 6:62 method using Nabertherm (Labotherm Program Controller S27). Further details relating to the analytical methods can be found in the work of Nguyen et al. ${ }^{3,14}$ In the present study, the HHV of the stored lignin-derived bio-oil is calculated from elemental data using Doulong's formula: ${ }^{21}$

$$
\mathrm{HHV}[\mathrm{MJ} / \mathrm{kg}]=\left[338.2 \times \% \mathrm{C}+1442.8 \times\left(\% \mathrm{H}-\frac{\% \mathrm{O}}{8}\right)\right] \times 0.001
$$

2.3.3. Bio-oil Fractionation. A block diagram describing the various steps of the solvent fractionation of lignin-derived bio-oils is shown in Figure 2. For each experimental run, the fractionation is performed according to the following two-step extraction procedure. The first step uses diethyl ether (DEE) as the solvent, and the second step uses THF as the solvent. Prior to filtrations, the glass filters are dried in the oven for $1 \mathrm{~h}$ at $105^{\circ} \mathrm{C}$ and cooled in a desiccator. In the first step, $\sim 10$ $\mathrm{g}$ of lignin-derived bio-oil are dissolved in DEE with an S/F ratio of $\sim 20$ and then filtered through Duran P4 glass filters (nominal maximum pore size of $10-16 \mu \mathrm{m}$ ); the solvent is removed from filtrates by means of a rotary vacuum evaporator (Büchi, R) operating at a temperature never exceeding $35^{\circ} \mathrm{C}$, while the filters are dried in the fume hood for 1 day. The DEE-soluble fraction obtained is called "light oil". In the second step, the aforesaid filters are now dissolved in THF with an S/F ratio of $\sim 40$ and filtered through Duran P4 glass filters; the solvent is removed from filtrates while the filters are dried in an oven for $1 \mathrm{~h}$ at $105{ }^{\circ} \mathrm{C}$, then cooled in the desiccator. This THFsoluble fraction obtained is called "heavy oil" and the THF-insoluble fraction obtained is called "solids".

2.3.4. Molecular Weight. The molecular weight of the oil and its fractions (light oil, heavy oil, and solids) was analyzed using gel 


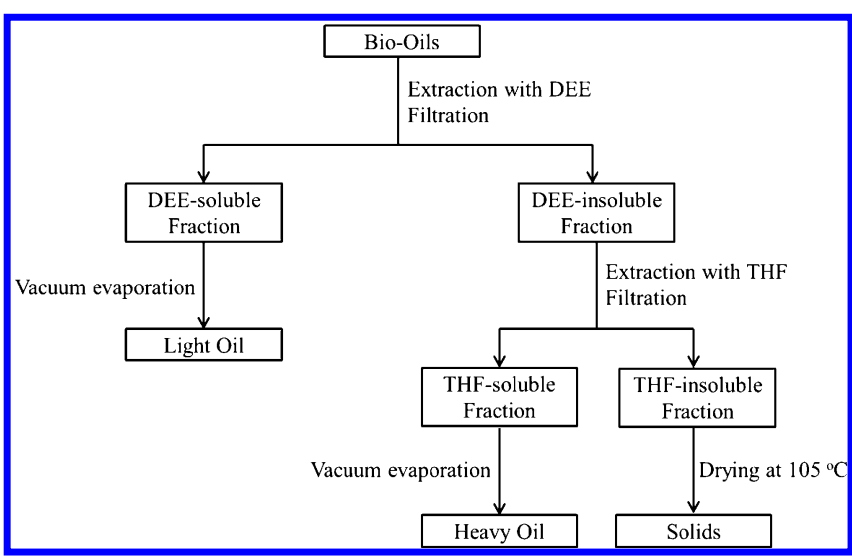

Figure 2. Block diagram of the solvent fractionation of the ligninderived bio-oils.

permeation chromatography (PL-GPC 50 plus) connected to refractive index (RI) and ultraviolet (UV) detectors $(280 \mathrm{~nm}$, Polymer Laboratories, Varian, Inc.). A PolarGel-M column and a guard column $(300 \times 7.5 \mathrm{~mm}$ and $50 \times 7.5 \mathrm{~mm}, 8 \mu \mathrm{m})$ were coupled in series and $\mathrm{DMSO} / \mathrm{LiBr}(10 \mathrm{mM})$ was used as the mobile phase. A 10-point calibration curve with Pullulan standards (polysaccharide calibrations kit, PL2090-0100, Varian) was used to determine the molecular weight $(\mathrm{Mw})$. The analyses were repeated twice and the average $\mathrm{Mw}$ was reported. Although the solids fraction of lignin-derived bio-oil is not soluble in THF, it is found to be soluble in the mobile phase (DMSO/ $\mathrm{LiBr}(10 \mathrm{mM}))$. The average value of the relative standard deviation of the response area was found to be $9.0 \%$.

2.3.5. Chemical Composition of the Light Oil. The lignin-derived bio-oils and light oils were extracted by DEE with an S/F ratio of $\sim 80$ / 1 and mixed with a known amount of internal standard solution IST (syringol in DEE). These mixtures were filtered through a $0.45 \mu \mathrm{m}$ syringe filter, and a light yellow clear DEE-rich phase was obtained. These phases were analyzed by means of gas chromatography (GC) (Agilent, Model 7890A) coupled with mass spectrometry (MS) (Agilent, Model 5975C). The main compounds were identified through the NIST MS Search Programme (Version 2.0) operating on the NIST/EPA/NIH Mass Spectral Database 2011 (NIST 11), with analytical standards being employed to confirm selected cases. In addition, the compounds identified were quantified on the basis of the IST (syringol). Further details of the method can be found in the work of Nguyen et al. ${ }^{13,14}$

\section{RESULTS AND DISCUSSION}

3.1. Bio-oil Fractionation and Yields. Figure 3 shows typical samples of the three fractions obtained from fresh ligninderived bio-oil after solvent fractionation. As can be seen, the light oil (DEE-soluble fraction) is a dark yellowish fluid, while the heavy oil (DEE-insoluble and THF-soluble) and solids (DEE-insoluble and THF-insoluble) are both blackish and solid states at room temperature. The solvent fractionation method used for the lignin-derived bio-oil provides a good estimation of the yield of the different fractions (see Table 3, presented later in this work). The yields are calculated from the mass on a dry oil basis. These data have not been reported previously, so it should be pointed out that the major part of fresh ligninderived bio-oil is light oil $(\sim 63 \%)$ and the remainder is composed of the high-Mw components of heavy oil (11\%) and solids (19\%). In addition, in our earlier works, we have reported that the yields of lignin-derived bio-oil, water-soluble organics, and char were $\sim 75 \%, \sim 9 \%$, and $\sim 19 \%$, respectively. ${ }^{13,14}$ Thus, the catalytic conversion of LignoBoost Kraft lignin in subcritical water $\left(290-370{ }^{\circ} \mathrm{C}, 25 \mathrm{MPa}\right)$, using phenol as the capping agent, $\mathrm{K}_{2} \mathrm{CO}_{3}(0.4 \%-2.2 \%)$, and $\mathrm{ZrO}_{2}$ as the

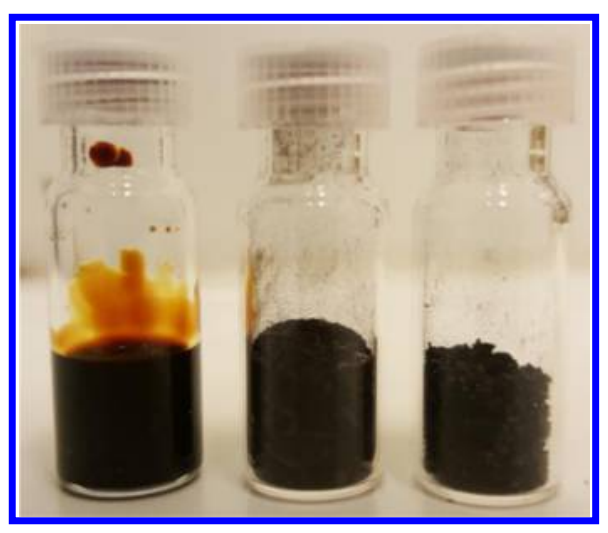

Figure 3. Typical samples of fresh light oil (left), heavy oil (middle), and solids (right) obtained from the lignin-derived bio-oil after solvent fractionation.

catalytic system gives $\sim 9 \%$ water-soluble organics (mainly monomers), $47 \%$ light oil (mainly monomers and dimers), $8 \%$ heavy oil (mainly oligomers), 20\% solids, and 19\% char.

The yields of light oil, heavy oil, and solids obtained from the lignin-derived bio-oils before and after two years of storage are reported in Table 3. Feeds with low concentrations of $\mathrm{K}_{2} \mathrm{CO}_{3}$ (Runs A and B, 0.4\%-1.0\%) gave yields of light oil, heavy oil, and solids that were relatively stable. When the $\mathrm{K}_{2} \mathrm{CO}_{3}$ concentration was increased (Runs $\mathrm{C}, \mathrm{D}$, and $\mathrm{F}-\mathrm{I}, 1.6 \%-$ $2.2 \%$ ), a clear trend could be observed: the yield of light oil decreased from $62 \% \pm 9 \%$ to $51 \% \pm 9 \%$, but that of heavy oil increased from $9 \% \pm 4 \%$ to $14 \% \pm 5 \%$ and of solids increased from $29 \% \pm 6 \%$ to $34 \% \pm 4 \%$ after 2 years of storage. In other words, the solids fraction in the lignin-derived bio-oils increased $\sim 15 \%$ after 2 years (high concentration of $\mathrm{K}_{2} \mathrm{CO}_{3}=1.6 \%-$ $2.2 \%)$. Chaala et al. ${ }^{17}$ observed that the solids content of biooils obtained by the vacuum pyrolysis of softwood bark increased from $0.55 \%$ to $0.84 \%$ after a storage period of 6 months, which represents an $\sim 53 \%$ increase in the solids content after 6 months. This result demonstrated that the aging of bio-oils obtained from lignin treated in subcritical water is slower than biomass-pyrolysis bio-oils. Interestingly, higher $\mathrm{K}_{2} \mathrm{CO}_{3}$ concentrations $(1.6 \%-2.2 \%)$ in the feed resulted in greater changes in yields of different fractions. More specifically, the light oil decreased $12.8 \%$ (from $69.6 \%$ to $60.7 \%$ ) in Run C and $15.6 \%$ (from $65.4 \%$ to $55.2 \%$ ) in Run D, while the solids increased $16.5 \%$ (from $26.0 \%$ to $30.3 \%$ ) in Run C and $21.6 \%$ (from $29.6 \%$ to $36.0 \%$ ) in Run D. The increase of $\mathrm{K}_{2} \mathrm{CO}_{3}$ concentration $(1.6 \%-2.2 \%)$ in the feed resulted in an increase in the ash or potassium content in the lignin-derived bio-oils, which affected its stability in the long-term storage (see Table 4 , presented later in this work). Thus, the effect of ash on the stability of lignin-derived bio-oil can be confirmed once again. Our data clearly show that the base concentration in the system affects the stability of the lignin-derived bio-oils. The heavy oil and solids increased during long-term storage, because of the formation of heavier compounds by the repolymerization of active compounds in the bio-oils. ${ }^{9,10}$ On the other hand, the temperature series do not show a clear trend in the changes in yield of the light oil, heavy oil, and solids.

3.2. Determination of Molecular Weight. Typical molecular weight curves of lignin-derived bio-oil and its fractions after 1 year of storage are given in Figure 4a. As can be seen, the lignin-derived bio-oil consists of a broad range of compounds ranging from a low-Mw peak (Peak 1) to a high- 
Table 3. Yield (\%) of Each Fraction in the Lignin-Derived Bio-Oils before and after 2 Years of Storage, Calculated on a Dry Oil Basis

\begin{tabular}{|c|c|c|c|c|c|c|c|c|c|}
\hline & A & B & C & $\mathrm{D}$ & $\mathrm{F}$ & $\mathrm{G}$ & $\mathrm{H}$ & C & I \\
\hline temperature, $T\left({ }^{\circ} \mathrm{C}\right)$ & 350 & 350 & 350 & 350 & 290 & 310 & 330 & 350 & 370 \\
\hline $\begin{array}{l}\mathrm{K}_{2} \mathrm{CO}_{3} \text { content }(\%) \\
\text { yield, fresh }(\%)\end{array}$ & 0.4 & 1.0 & 1.6 & 2.2 & 1.6 & 1.6 & 1.6 & 1.6 & 1.6 \\
\hline light oil & 68.5 & 62.9 & 69.6 & 65.4 & 46.8 & 59.4 & 49.5 & 69.6 & 72.0 \\
\hline heavy oil & 23.6 & 11.2 & 4.4 & 4.9 & 14.4 & 11.2 & 13.9 & 4.4 & 9.5 \\
\hline solids & 7.9 & 25.9 & 26.0 & 29.6 & 38.8 & 29.4 & 36.5 & 26.0 & 18.5 \\
\hline \multicolumn{10}{|l|}{ yield, stored (\%) } \\
\hline light oil & 68.2 & 62.2 & 60.7 & 55.2 & 42.6 & 50.6 & 34.6 & 60.7 & 55.4 \\
\hline heavy oil & 24.9 & 12.8 & 9.0 & 8.8 & 18.6 & 17.7 & 23.9 & 9.0 & 13.8 \\
\hline solids & 6.8 & 25.0 & 30.3 & 36.0 & 38.8 & 31.7 & 41.5 & 30.3 & 30.7 \\
\hline
\end{tabular}

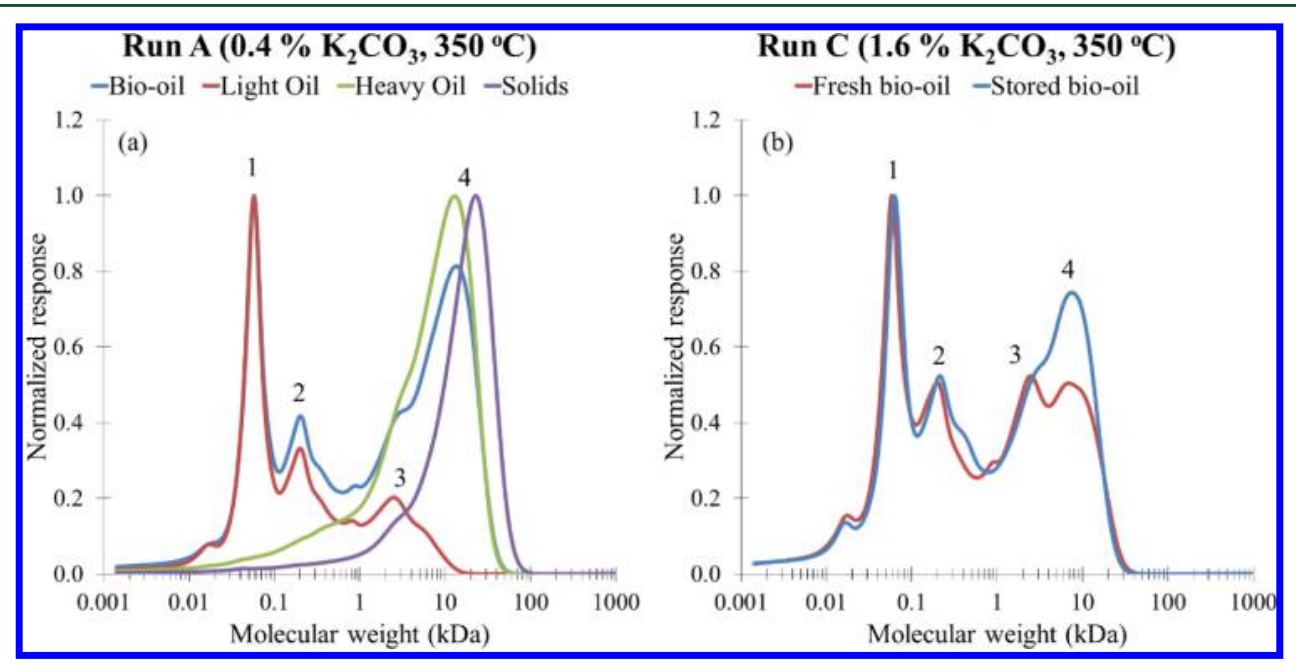

Figure 4. Typical molecular weight ( $\mathrm{Mw}$ ) curves of (a) lignin-derived bio-oil and its fractions (light oil, heavy oil, and solids) after 1 year of storage and (b) lignin-derived bio-oil before and after 1 year of storage.

Mw peak (Peak 4). The light oil comprises the lowest-Mw component (Peaks 1 and 2) of the lignin-derived bio-oil and the heavy oil and solids comprise the highest-Mw component (Peaks 3 and 4). The light oil comprises a high amount of monomers (Peak 1, $\sim 60 \mathrm{Da}$ ) and a low amount of dimers (Peak 2, 250 Da) and oligomers (Peak 3, 1800 Da). The heavy oil comprises mainly oligomers with a low amount of $1800 \mathrm{Da}$ (Peak 3) and a higher amount of $10000 \mathrm{Da}$ (Peak 4). The typical $\mathrm{Mw}$ curves of the lignin-derived bio-oil before and after 1 year of storage are shown in Figure $4 \mathrm{~b}$. Here, it can be seen that, after 1 year of storage, the content of the low-Mw material decreases while that of the high-Mw material increases. In particular, Peak 3 shifts toward Peak 4 (the higher $\mathrm{Mw}$ peak), indicating that the low-Mw components react because of the polymerization or condensation reactions that occur between the components of the lignin-derived bio-oil and their Mw increases. The proportion of high-Mw material in the lignin-derived bio-oil thus becomes greater, resulting in an increase in the average $\mathrm{Mw}$ of the stored bio-oil. ${ }^{10,17,19}$ The formation of high-Mw material is also shown by the fractionation of lignin-derived bio-oil and the yields obtained (see Table 3). The chemical properties of lignin-derived bio-oil clearly change during long-term storage and thereby cause it to be unstable.

3.3. Elemental Composition of the Bio-oil Used. The water content and elemental composition of the lignin-derived bio-oils (calculated on a dry oil basis) used before and after 2 years of storage are reported in Table 4. Generally, the water content increased from $1.7 \%$ to $6.3 \%$ after 2 years of storage at ambient temperature. This observation is in an agreement with the results from the literature on biomass-pyrolysis biooil. ${ }^{9,17,18}$ However, the water content decreased from $9.8 \%$ to $7.1 \%$ in Run $\mathrm{F}$ (the run at the lowest operating temperature, $290{ }^{\circ} \mathrm{C}$ ); the reason for this observation is not known.

The elemental changes that occurred in the lignin-derived bio-oil during long-term storage were relatively small, even though this trend was not observed consistently in all of the runs. As can be seen, the trends that can be observed clearly at the operating temperature of $350{ }^{\circ} \mathrm{C}$ (Runs A-D, see Table 4) are that the carbon content decreases from $75 \% \pm 0 \%$ to $71 \%$ $\pm 0 \%$, while the oxygen content increases from $16 \% \pm 1 \%$ to $19 \% \pm 0 \%$. The later can be explained by $\mathrm{O}_{2}$ leakage during storage. Also, the contents of both sulfur and ash are kept relatively stable. Moreover, the $\mathrm{O} / \mathrm{C}$ ratio increases from $0.21 \%$ $\pm 0.01 \%$ to $0.27 \% \pm 0.01 \%$ after storage, while the $\mathrm{H} / \mathrm{C}$ ratio is more or less stable, demonstrating that the oxidation reactions may occur during storage.

The other operating temperatures do not show any clear tendencies on the change of elemental composition of ligninderived bio-oils. This may be due to the different structures of the lignin-derived bio-oils obtained from the different operating temperatures. The results observed at $290{ }^{\circ} \mathrm{C}$ differed from those at $350{ }^{\circ} \mathrm{C}$ : the carbon content increases from $70 \%$ to $73 \%$, whereas oxygen decreases from $21 \%$ to $17 \%$. In the other runs (at $310{ }^{\circ} \mathrm{C}, 330$ and $370{ }^{\circ} \mathrm{C}$ ), the carbon, hydrogen, and oxygen contents are relatively stable. These findings demon- 
Table 4. Water Content, Elemental Composition, and High Heating Value (HHV) of the Lignin-Derived Bio-oils (Calculated on a Dry Oil Basis) before and after 2 Years of Storage

\begin{tabular}{|c|c|c|c|c|c|c|c|c|c|}
\hline & A & B & $\mathrm{C}$ & $\mathrm{D}$ & $\mathrm{F}$ & G & $\mathrm{H}$ & $\mathrm{C}$ & I \\
\hline $\mathrm{K}_{2} \mathrm{CO}_{3}(\%)$ & 0.4 & 1.0 & 1.6 & 2.2 & 1.6 & 1.6 & 1.6 & 1.6 & 1.6 \\
\hline temperature, $T\left({ }^{\circ} \mathrm{C}\right)$ & 350 & 350 & 350 & 350 & 290 & 310 & 330 & 350 & 370 \\
\hline \multicolumn{10}{|l|}{ fresh } \\
\hline moisture content (\%) & 1.2 & 1.1 & 2.0 & 1.8 & 9.8 & 1.3 & 2.4 & 2.0 & 2.1 \\
\hline \multicolumn{10}{|l|}{ composition (\%) } \\
\hline $\mathrm{C}$ & 74.6 & 74.2 & 74.9 & 74.8 & 70.0 & 72.6 & 73.9 & 74.9 & 76.0 \\
\hline $\mathrm{H}$ & 6.9 & 6.9 & 6.6 & 6.5 & 6.5 & 6.4 & 6.1 & 6.6 & 6.8 \\
\hline$S$ & 0.4 & 0.4 & 0.4 & 0.3 & 0.4 & 0.5 & 0.6 & 0.4 & 0.3 \\
\hline ash & 1.0 & 2.1 & 2.8 & 3.5 & 2.4 & 2.0 & 2.4 & 2.8 & 1.8 \\
\hline $\mathrm{O}^{a}$ & 17 & 16 & 15 & 15 & 21 & 18 & 17 & 15 & 15 \\
\hline $\mathrm{K}$ & 0.5 & 1.0 & 1.6 & 1.9 & 1.5 & 1.4 & 1.7 & 1.6 & 1.4 \\
\hline $\mathrm{H} / \mathrm{C}$ & 0.09 & 0.09 & 0.09 & 0.09 & 0.09 & 0.09 & 0.08 & 0.09 & 0.09 \\
\hline $\mathrm{O} / \mathrm{C}$ & 0.23 & 0.22 & 0.20 & 0.20 & 0.30 & 0.25 & 0.23 & 0.20 & 0.20 \\
\hline high heating value, HHV (MJ/kg) & 31.9 & 31.8 & 31.9 & 31.9 & 31.7 & 31.1 & 31.0 & 31.9 & 32.7 \\
\hline \multicolumn{10}{|l|}{ stored } \\
\hline moisture content (\%) & 4.5 & 3.0 & 8.7 & 10.7 & 7.1 & 6.3 & 2.4 & 8.7 & 5.7 \\
\hline \multicolumn{10}{|l|}{ composition (\%) } \\
\hline $\mathrm{C}$ & 71.3 & 71.5 & 71.5 & 71.5 & 72.6 & 72.0 & 74.0 & 71.5 & 75.0 \\
\hline $\mathrm{H}$ & 6.7 & 6.8 & 6.2 & 6.0 & 6.4 & 6.3 & 5.5 & 6.2 & 7.0 \\
\hline$S$ & 0.4 & 0.3 & 0.3 & 0.2 & 0.4 & 0.4 & 0.5 & 0.3 & 0.3 \\
\hline ash & 1.0 & 1.9 & 2.7 & 3.4 & 3.0 & 2.4 & 3.6 & 2.7 & 2.5 \\
\hline $\mathrm{O}^{a}$ & 20 & 19 & 19 & 19 & 17 & 19 & 16 & 19 & 15 \\
\hline $\mathrm{K}$ & 0.5 & 1.0 & 1.2 & 1.8 & 1.2 & 1.1 & 1.5 & 1.2 & 0.9 \\
\hline $\mathrm{H} / \mathrm{C}$ & 0.09 & 0.10 & 0.09 & 0.08 & 0.09 & 0.09 & 0.07 & 0.09 & 0.09 \\
\hline $\mathrm{O} / \mathrm{C}$ & 0.28 & 0.27 & 0.27 & 0.27 & 0.23 & 0.26 & 0.22 & 0.27 & 0.20 \\
\hline high heating value, $\mathrm{HHV}^{b}(\mathrm{MJ} / \mathrm{kg})$ & 30.2 & 30.6 & 29.7 & 29.4 & 30.7 & 30.0 & 30.1 & 29.7 & 32.8 \\
\hline
\end{tabular}

${ }^{a}$ Oxygen is calculated by difference. ${ }^{b}$ Heating value is calculated from the $\mathrm{C}, \mathrm{H}$, and $\mathrm{O}$ contents.

strate that the bio-oil obtained from lignin treated under subcritical water conditions is relatively stable during long-term storage. Moreover, the heating value decreases from 32\% to $30 \%$ in all of the runs after long-term storage, because of the change in the elemental composition of lignin-derived bio-oil.

3.4. Chemical Composition of the Light Oil. The DEEsoluble fractions of the lignin-derived bio-oils and light oils were analyzed using GC-MS. Figure 5 shows a typical GC-MS TIC of the DEE extracts of the oil before and after 2 years of storage from Run A. The main compounds before and after 2 years of storage are identified, quantified, and reported in Table 5. The yield of each compound detected by GC-MS in the lignin-derived bio-oils is calculated on a dry oil basis. Generally, there is an increase in the yields of anisole (from 3\% to 4\%) and phenol (from $12 \%$ to $15 \%$ ) and a decrease in alkylphenols (from $4 \%$ down to $3 \%$ ), catechols (from $0.5 \%$ down to $0 \%$ ), $9 \mathrm{H}$-xanthene (from $0.2 \%$ down to $0 \%$ ), and phenolic dimers (from $3 \%$ down to $1 \%$ ), along with minor changes in alkylanisoles, guaiacols, and isopropyl-methyl-phenanthrene or rentene (see Figure 6). However, some variations can be detected in some of the individual runs: e.g., the amount of anisole decreases in Runs $\mathrm{D}$ and $\mathrm{H}$ (from $6 \% \pm 2 \%$ to $3 \% \pm$ $2 \%)$ and the amount of phenol decreases in Runs C and D (from $15 \% \pm 2 \%$ to $11 \% \pm 0 \%$ ) (see Table 5). These variations may be due to the complex kinetics of various reactions that occur during storage. Nevertheless, a clear trend of a decrease in the yields of alkylphenols, catechols, and $9 \mathrm{H}$-xanthene in the lignin-derived bio-oil after the storage can be observed.

Figure 7 shows a summary of data found in the literature of the stability of pure phenol and phenol derivatives at ambient temperature. $^{22-26}$ As can be seen, alkylphenols, catechols, and phenolic dimers are much more reactive than anisoles and guaiacols: this was also confirmed in the present study. The stability of anisoles and guaiacols is enhanced by an aryl-ether linkage, instead of a reactive hydroxyl group. ${ }^{22}$ Phenol is known as being a high reactive compound: the excess of electrons in the aromatic ring at the ortho and para positions makes it very sensitive to electrophilic substitution. ${ }^{23}$ Alkylphenols, catechols, and phenolic dimers, on the other hand, exhibit an enhanced reactivity, compared to phenol. These compound classes have been reported to be discolored in the presence of atmospheric oxygen with time, and especially in the presence of light, elevated temperatures, and traces of heavy metals, dissolved alkali, and moisture. ${ }^{22,24} 9 \mathrm{H}$-Xanthene is composed of two benzene rings fused to tetrahydropyran, which is a sixmembered cyclic ether. This ether bond between aromatic phenols is very stable. However, the presence of both aromatic and methylene groups makes this compound unstable, allowing substitution to occur via oxidation and hydrogenation. ${ }^{25,26}$

Consequently, lignin-derived bio-oils are not as chemically stable as conventional fossil fuels when stored long-term at ambient temperature. However, they are more chemically stable than bio-oils derived from biomass pyrolysis. ${ }^{9,10}$ Yang et al. ${ }^{10}$ and Chen et al. ${ }^{9}$ have stated that the presence of highly active organic functional groups (such as carbonyl, hydroxyl, phenol, and unsaturated carbon-carbon bonds) and solid residues (such as oxides and salts of metals) result in chemical reactions (e.g., polymerization, condensation and esterification) that continue to occur during storage.

In addition, the total yield of compounds (excluding phenol) identified from the GC-MS analysis of the stored lignin-derived bio-oils decreased from $15 \%$ to $11 \%$. Ben and Ragauskas ${ }^{27}$ 


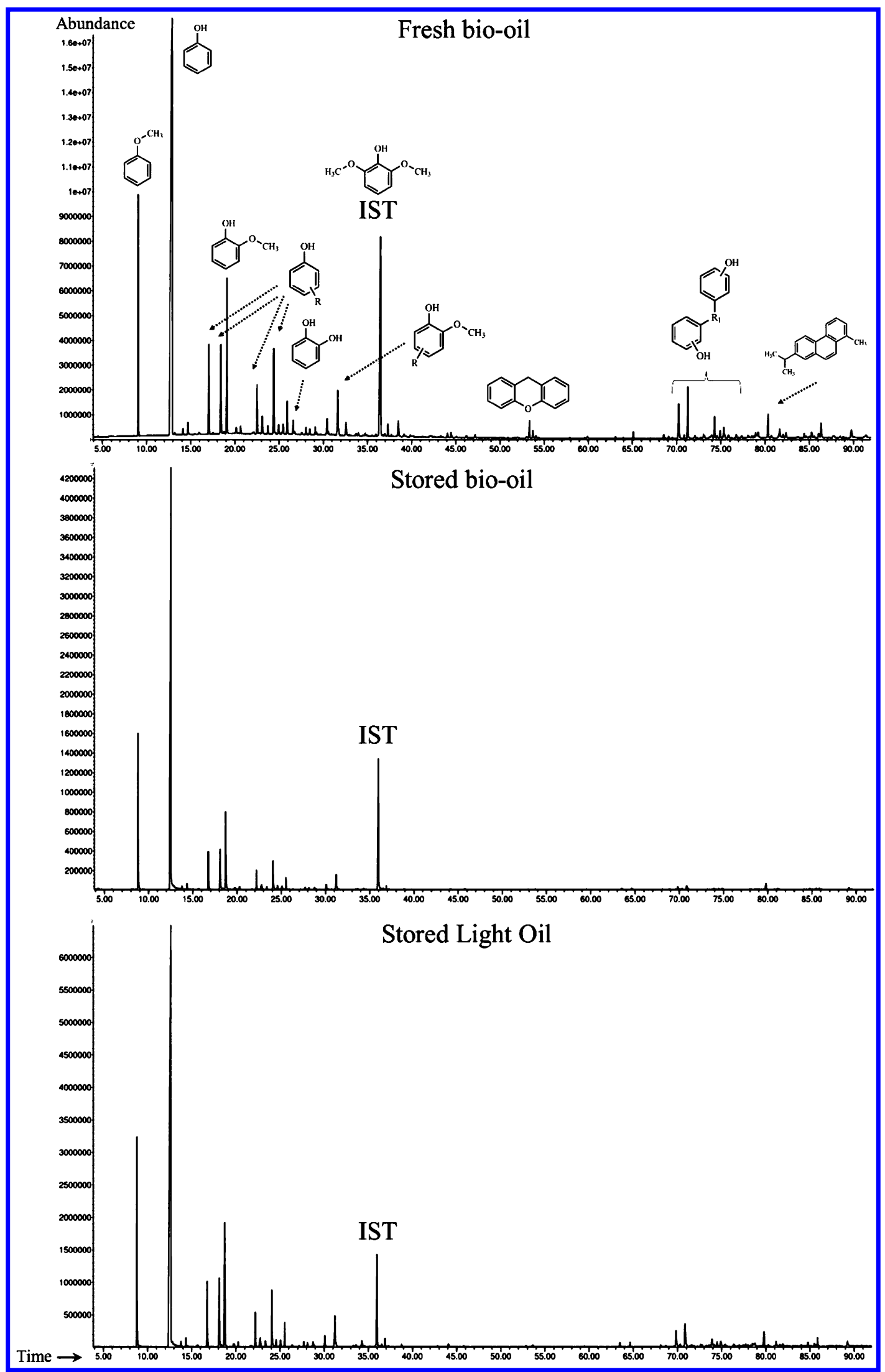

Figure 5. Typical GC-MS TIC of the DEE extracts of the fresh lignin-derived bio-oil, stored lignin-derived bio-oil and stored light oil from Run A.

suggested that aryl condensation reactions occurring in biomass-pyrolysis bio-oil during 1 year of aging at room temperature resulted in a decrease in the aromatic proton content, which supports our results. However, the corresponding decrease for the stored light oil was a mere $1 \%$, i.e., from $15 \%$ to $14 \%$. This shows that the stored light oil has a more 


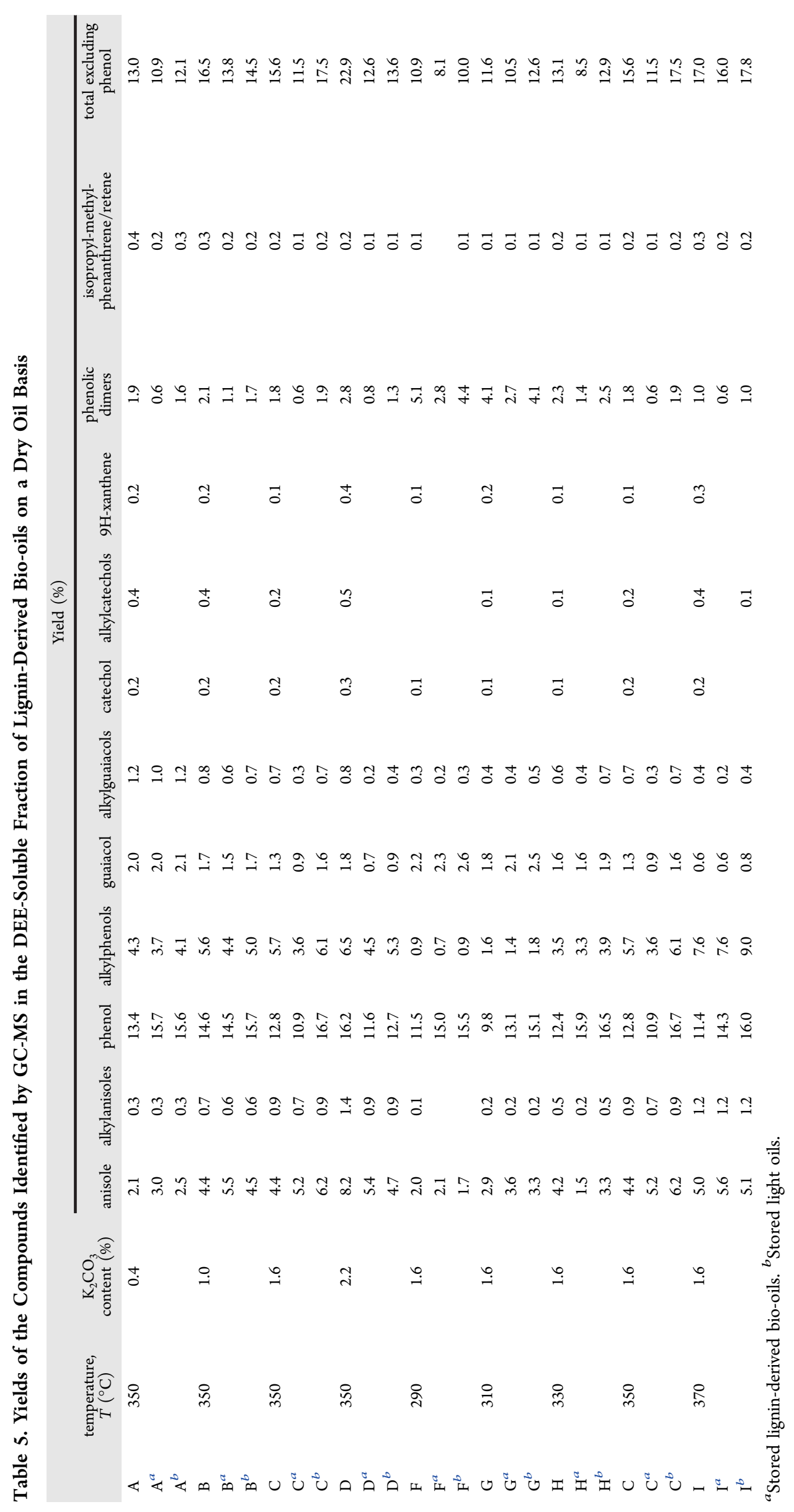




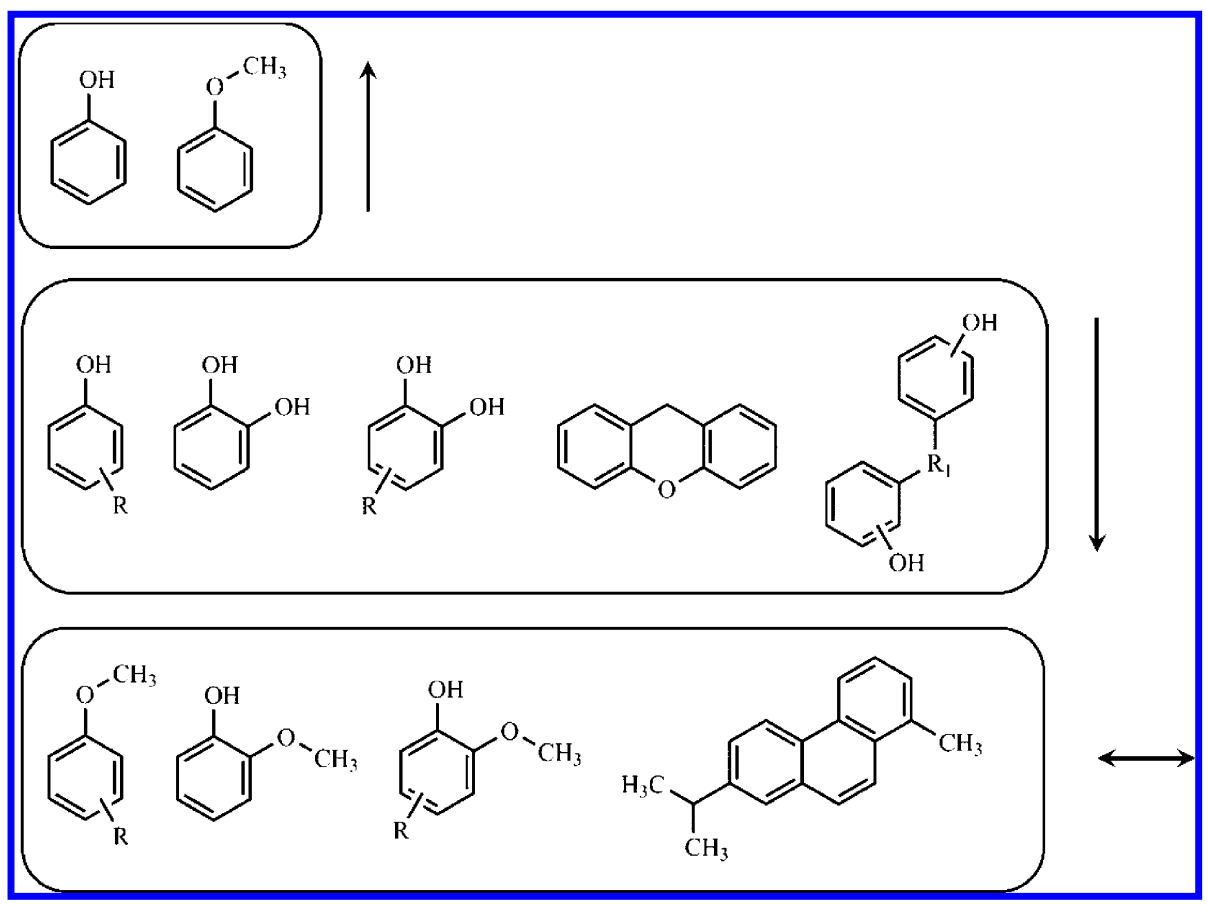

Figure 6. General variations in the different compounds identified by gas chromatography-mass spectrometry (GC-MS) in the light oil after longterm storage.

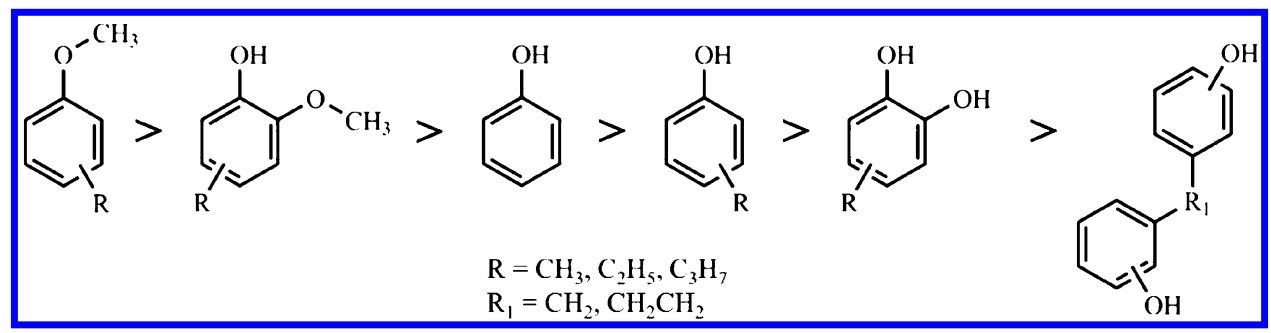

Figure 7. Order of stability of pure phenolic compounds at ambient temperature.

stable chemical composition than the stored lignin-derived biooil, which may be due to the fact that the latter contains a certain amount of solids. This is very consistent with the results reported by Yang et al. ${ }^{10}$ and Chen et al. ${ }^{9}$ These authors concluded that the solid particles and/or ash in pyrolysis bio-oil contain inorganic elements (e.g., potassium, calcium, sodium, magnesium, silicon, phosphorus, and chlorine) that act as a catalyst in polymerization and condensation, and thereby affect its stability negatively. This result suggests that removing solids from lignin-derived bio-oil could potentially retard the aging process or enhance its stability. However, a complete removal of solids is very difficult, since it is difficult to remove the fine trapped particles in the compounds. ${ }^{9,10}$ It is interesting to note that greater decreases in the total yield of GC-MS-identified compounds are observed when the $\mathrm{K}_{2} \mathrm{CO}_{3}$ concentration in the feed increases from $0.4 \%$ to $2.2 \%$. For instance, this value in Run A decreased by $\sim 16 \%$ (from $13 \%$ to $11 \%$ ) and in Run D decreased by $\sim 45 \%$ (from $23 \%$ to $14 \%$; see Table 5). This may be caused by the ash content in the lignin-derived bio-oils from these runs increasing from $1.0 \%$ to $3.5 \%$, which promotes catalytic depolymerization reactions. ${ }^{10}$ Therefore, the effect of ash on the stability of lignin-derived bio-oil is found to be in agreement with earlier results. Lignin-derived bio-oil is more stable if it has low contents of solids or ash (i.e., its stability can be improved by removing solids or ash).

\section{CONCLUSIONS}

The stability of lignin-derived bio-oil from catalytic depolymerization and conversion in subcritical water $(25 \mathrm{MPa}, 290-370$ ${ }^{\circ} \mathrm{C}$ ) that has been stored for 1-2 years under ambient temperature and normal atmosphere conditions was investigated. It was shown that (i) the base concentration of the feed solution affects the stability of the lignin-derived bio-oil during long-term storage, and (ii) the aging process of the ligninderived bio-oil increases when the base content of the feed increases. After storage, the yields of high-molecular-weight (high-Mw) structures (heavy oil and solids) were found to be slightly increased and those of low-molecular-weight (low-Mw) structures (light oil) slightly decreased. It may be concluded that (i) oxygen was incorporated into the lignin-derived bio-oil structure and (ii) oxidation was one of the aging reactions that occurred. It could also be concluded that solid particles have a high impact on the stability of lignin-derived bio-oil: it suggests that their removal would be beneficial in retarding the aging process and enhancing the stability of the lignin-derived bio-oil. Furthermore, decreases in the yield of some compound classes (alkylphenols, catechols, and 9H-xanthene) were found after 2 years of storage, showing consistency with the stability of phenolic series found in the literature. These findings indicate that (i) lignin-derived bio-oil is relatively stable during long- 
term storage and (ii) it has better stability than bio-oil that has been derived from the fast pyrolysis of biomass.

\section{AUTHOR INFORMATION}

\section{Corresponding Author}

*Tel.: +46 31772 2992. Fax: +46 31772 2995. E-mail: hanst@ chalmers.se.

\section{Notes}

The authors declare no competing financial interest.

\section{ACKNOWLEDGMENTS}

We are grateful to the Chalmers Energy Initiative-LignoFuel Project, Valmet Power AB, The Swedish Energy Agency, and the Ångpanneförenings Forskningsstiftelse Research Foundation for their financial support. Our thanks go to Tommy Friberg for his technical assistance.

\section{REFERENCES}

(1) Sofer, S. S.; Zaborsky, O. R. Biomass sources. In Biomass Conversion Processes for Energy and Fuels; 1st Edition; Plenum Press: New York, 1981.

(2) Henriksson, G. Lignin. In Pulp and Paper Chemistry and Technology. Vol 1, Wood Chemistry and Wood Biotechnology; Gellerstedt, M., Henriksson, G., Eds.; Walter de Gruyter: Berlin, 2009.

(3) Sjöström, E. Wood polysaccharides. In Wood Chemistry. Fundamentals and Applications, 2nd Edition; Academic Press: San Diego, CA, 1993.

(4) Sofer, S. S.; Zaborsky, O. R. Conversion processes. In Biomass Conversion Processes for Energy and Fuels, 1st Edition; Plenum Press: New York, 1981.

(5) Grioui, N.; Halouani, K.; Agblevor, F. A. Eneroy Sustainable Dev. 2014, 21, 100-112.

(6) Bridgwater, A. V.; Meier, D.; Radlein, D. Org. Geochem. 1999, 30, 1479-1493.

(7) Ward, J.; Rasul, M. G.; Bhuiya, M. M. K. Procedia Eng. 2014, 90, 669-674.

(8) Abedi, J.; Nourozieh, H.; Kariznovi, M.; Seyedeyn-Azad, F. Can. I. Chem. Eng. 2015, 93, 500-509.

(9) Chen, D.; Zhou, J.; Zhang, Q.; Zhu, X. Renewable Sustainable Energv Rev. 2014, 40, 69-79.

(10) Yang, Z.; Kumar, A.; Huhnke, R. L. Renewable Sustainable Energy Rev. 2015, 50, 859-870.

(11) Pandey, M. P.; Kim, C. S. Chem. Eng. Technol. 2011, 34, $29-41$.

(12) Vigneault, A.; Johnson, D. K.; Chornet, E. Can. I. Chem. Eng. 2007, 85, 906-916.

(13) Nguyen, T. D. H.; Maschietti, M.; Åmand, L.-E.; Vamling, L.; Olausson, L.; Andersson, S.-I.; Theliander, H. Bioresour. Technol. 2014, 170, 196-203.

(14) Nguyen, T. D. H.; Maschietti, M.; Belkheiri, T.; Åmand, L.-E.; Theliander, H.; Vamling, L.; Olausson, L.; Andersson, S.-I. L. Supercrit. Fluids 2014, 86, 67-75.

(15) Bridgwater, A. V. Environ. Prog. Sustainable Energy 2012, 31, 261-268.

(16) Zhang, Q.; Chang, J.; Wang, T.; Xu, Y. Energy Convers. Manage. 2007, 48, 87-92.

(17) Chaala, A.; Ba, T.; Garcia-Perez, M.; Roy, C. Energy Fuels 2004, $18,1535-1542$.

(18) Oasmaa, A.; Kuoppala, E. Energy Fuels 2003, 17, 1075-1084.

(19) Czernik, S.; Johnson, D. K.; Black, S. Biomass Bioenergy 1994, 7, $187-192$.

(20) Czernik, S.; Bridgwater, A. V. Energy Fuels 2004, 18, 590-598.

(21) Jiang, X.; Zhong, Z.; Ellis, N.; Wang, Q. Chem. Eng. Technol. 2011, 34, 727-736.

(22) Fiege, H.; Voges, H.-W.; Hamamoto, T.; Umemura, S.; Iwata, T.; Miki, H.; Fujita, Y.; Buysch, H.-J.; Garbe, D.; Paulus, W. Phenol derivatives. In Ullmann's Encyclopedia of Industrial Chemistry, 7th Edition; John Wiley and Sons: New York, 2000.
(23) Weber, M.; Weber, M.; Kleine-Boymann, M. Phenol. In Ullmann's Encyclopedia of Industrial Chemistry, 7th Edition; John Wiley and Sons: New York, 2000.

(24) Fiege, H. Cresols and xylenols. In Ullmann's Encyclopedia of Industrial Chemistry, 7th Edition; John Wiley and Sons: New York, 2000.

(25) Schmidt, R.; Griesbaum, K.; Behr, A.; Biedenkapp, D.; Voges, H.-W.; Garbe, D.; Paetz, C.; Collin, G.; Mayer, D.; Höke, H. Hydrocarbons. In Ullmann's Encyclopedia of Industrial Chemistry, 7th Edition; John Wiley and Sons: New York, 2000.

(26) Li, J.-K.; Huang, X.-Q.; Yang, S.; Ma, H.-W.; Chi, Y.-N.; Hu, C.W. Inorg. Chem. 2015, 54, 1454-1461.

(27) Ben, H.; Ragauskas, A. I. ChemSusChem 2012, 5, 1687-1693. 